\title{
Trans-Cultural Journeys of East-Asian Educators: The Impact of the Three Teachings
}

\author{
Nguyen Hoang Giang-Le \\ Brock University, \\ St. Catharines, Ontario, Canada
}

\author{
Chieh-Tai Hsiao, Youmi Heo \\ Thompson Rivers University, \\ Kamloops, BC, Canada
}

\begin{abstract}
This paper presents the joint journeys, from the East to the West, of three emerging educators, who reflect on their lived experiences in an Asian educational context and their shaped identities through a connection between the motherland and the places to which they immigrated. They have grounded their identities in the inequities they experienced in Asian education and described their experiences through a cultural and social lens as Asian teachers studying in Canadian institutions. They story their lived experiences by using a Photovoice research method to elicit the narratives of their East-to-West transcultural journeys. The major finding is the reconstructed identity of each of the researchers. The data collected through 'Photovoice' sheds light on the influence on teachers' mindset of the Three Teachings or ReligionsBuddhism, Confucianism, and Taoism - across Asia on teachers' mindset, which are seen to cause inequities among the marginalized. The purpose of this research is an attempt by the authors, who have immersed themselves in each other's journeys, to discuss how they have reformed their educator identities in a Canadian educational context in which equity, diversity, and inclusion are acknowledged.
\end{abstract}

\section{Introduction}

Education enlightens the essence of humanity and enhances the prosperity of human civilization. According to John Dewey, meliorism refers to the belief that the specific conditions in each moment can be bettered by human effort [1]. It encourages humans to learn and grow to improve the world through active participation in the movement for social change. John Dewey also claimed that dualistic epistemology disconnects learning from life and nature [1]. Establishing harmony and balance in educating the theory of experiential learning was his pragmatic approach to education. With regard to overcoming dichotomy in education, Dewey had a similar view concerning Eastern philosophies, including Confucianism, Taoism, and Buddhism. For instance, Taoists believe that one can harmonize with nature through the balance of dualistic cosmic energies called Yin Yang, whereas Buddhists and Confucians believe that all beings are interconnected and that people have to overcome a self-centered perspective [2].

By sharing our East-to-West journeys, we believe there are reciprocal relationships between a landscape and its dwellers. Our stories support and broaden the definition of landscape identity as a social and personal construction [3]. A collage of our lived experiences through photos creates a mosaic, highlighting the inequities imposed on the marginalized populations caused by the impact of the Three Teachings/Religions principles in Asia.

The research questions are (1) How do the three teachings influence the perception of social injustice in East Asian contexts? (2) Can the arts contribute to social justice advocacy?

Sharing the lived experiences and visualizing the stories through a Photo-voice research methodology, we have come to enlightenment in our perspectives of social justice in a North American educational context. This had enabled us to identify a reform of the self within each of us thanks to changing social contexts.

\section{Theoretical Framework}

It is critical to start the paper with a succinct overview of the interconnection between the landscape and individual identity and the Photovoice research approach. We aim to analyze how the identity of an inhabitant can be affected by the land where he or she is living. In the interim, the dwellers have a significant impact on the places. However, it is possible for people to reflect on what they acquired in their home countries and then reconstruct their social identities through the transcultural journey.

Our social location is defined by our current position, which is influenced by the social circumstances of our past experiences [4]. As such, the cultural influence of landscape and our past learning has profoundly impacted us as emerging 
educators throughout the East-to-West educational journeys. Our transformed epistemology in Western education facilitates our mindsets of teaching and learning by enabling us to analyze the influence of our past-to-current beliefs in education. By reflecting on our social location and examining our past learning, it seeks to question the validity of social conformities, thereby enabling us to develop the consciousness on issues of inclusion and social justice.

The theoretical framework centers educator identities development and examines the social issues of Asian teachings. Bringing light to issues of social inequity derived from self and others' experiences is an attempt to identify the preeminence of judgment and abuse in Asian education. Without gaining an adequate understanding of the issues of education in the motherlands, it is difficult for us to define our educator identities and forward our knowledge for future learners and educators. Because our study applies the Photo-voice method, we will introduce the in-depth knowledge of the Photo-voice approach and explain the reason why it is our choice of research methodology.

\subsection{Landscape and Individual Identity}

Stobbelaar and Pedroli [5] defined landscape identity "as the perceived uniqueness of a place" ( $p$. 322) and clarified a constant interaction between people and landscape. The identity of the inhabitants and the identity of the land where people dwell are interdependent on one another [6]. The construction of self within people stems from interaction with the surroundings, such as social and cultural norms, religion, ethnicity, and gender [6].

Social identity theory was developed by Henri Tajfel and John Turner to understand the psychological basis for intergroup discrimination [7]. According to the theory, we naturally trust and care for our own as best as we can to maintain a sense of belonging in the group. It can lead to intergroup discrimination towards otherness. Noticeably, the social identity of people may change under the influence of changing contexts in that the oppressed can become the oppressor in the dynamic power shift of a multifaceted society over the course of history [8].

We, as immigrants to Canada from three Asian countries-Vietnam, Taiwan, and South Koreabrought many common values and beliefs of the East to the West when examining the unfamiliar social and educational phenomena. From the perspectives of young educators, we have defined unfamiliarity as the conflict of the educational principles between the East and the West.

\subsection{The Three Teachings}

Confucianism, Taoism, and Buddhism have served as great religions and cultural foundation in East Asia for thousands of years. Confucianism focuses on social harmony in human relations; Taoism emphasizes a person's relationship with nature, and Buddhism offers a new outlook on human life and the spiritual realm [9]. Although the three teachings have strategic differences, they have the same goals of the human potential for achieving selfactualization.

Confucianism was developed by the Chinese philosopher Master Kong in 551-479 B.C., and it consists of two parts, $l i$, the social roles and behaviour, and ren, the cultivation of humanity [2]. Ideal selfhood in Confucianism can be actualized by harmonizing well with others through strict social order and appropriate behaviours including kindness, righteousness, etiquette, loyalty, and filial piety [9]. However, a strict hierarchical social order in Confucianism can be a drawback as it inhibits the development of one's individuality in social interactions with others [10]. For instance, people who behave or think differently from the social norms due to their different beliefs or physical, and psychological conditions can be perceived as being disharmony with society. Accordingly, those who cannot get along well with others because of their differences are easily excluded from society, which is considered as shameful, with loss of face, in their social groups in the collectivist Asian context [10].

Taoism was created by Laozi in China around the sixth century B.C., emphasizing individual freedom and spontaneity to live with Tao "the path" [2]. According to Csikszentmihalyi, one can unify with the Tao, a timeless and indescribable moment of flow, through complete absorption in what one does, which is often interpreted as action without effort [11].

Another important concept of Taoism is the balance of Yin and Yang, which are two opposing yet complementary forces of the universe [2]. It explains that everything exists in pairs as a perfect symmetry with each other in the human, social, and natural worlds. According to this belief, it may be inevitable to see social injustice by means of understanding social justice within the cycles, rhythms, and patterns of the wider cosmic order. This idea may mislead people to have a passive attitude towards social transformation by misinterpreting social injustice as a necessary evil in human life. Interestingly, this idea has also influenced Chinese traditional medicine. Taoists believe that health is an optimal state of harmonious interaction between Yin and Yang, whereas illness is disharmony of the dual energies within one's body and spirit [12]. Therefore, people with physical and 
mental disabilities tend to be viewed as abnormal or invalid in East Asia [10, 12].

In Buddhism, which was created by Sakyamuni in India around the 6th century B.C., the ultimate purpose of life is to attain inner peace through the experience of enlightenment, often described as nirvana or liberation [13]. Buddhists' notion of the individual self is nothing but an illusion and holding onto the self-image is the source of suffering [9]. To cease the illusion of selfhood, one should be fully awakened to think, talk, and behave consciously. Often, meditation and compassion are used as tools to live in awareness and experience as part of the collective wholeness [13].

Importantly, Buddhists believe the concept of Samsara and Karma. The former means the cycle of birth and rebirth, while the latter means a consequence of one's good or bad deeds [2]. However, these ideas would be a source of negative interpretation of hardships among the marginalized in that the hardships are regarded as the result of punishment of wrongdoings in people's previous lives [10].

Despite the overall status of the three teachings that have guided many to exercise self-cultivation while harmonizing with people, society and even nature, social injustice is still rampant in East Asia. One of the reasons would be limited knowledge to interpret the three teachings correctly. The misinterpretation of the three teachings could mislead people in East Asia to justify social discrimination towards marginalized groups as a type of shame, illness and a result of one's wrongdoings in a previous life.

\subsection{Inequities in Asian Education}

We each use the first person "I" to re-tell our stories in three different Asian countries: Vietnam, Taiwan, and South Korea. Conceiving of the singular perceptions of time and space allows us to explore the land in different ways [14]. It is also our purpose to give each other equal personal space to speak to the stories, express the pure feelings we might have, and, significantly offer readers an opportunity to live in the authors' stories with diverse nuances. In this way, the researchers can make connections with the readers by linking with others' lived experiences.

Our stories utilize images to represent the essence of social transformation through a visual rhetoric with viewers. We pay attention to the voices emerging from the photographs and critically examine the social inequalities derived from the Three Teachings by reflecting upon our experiences as learners and educators. The implications of these social inequalities are a discrepancy which consists of hegemonic beliefs of credulity and perceive the marginalized groups as inferior to the privileged throughout the progression of cultural discourse [15].
Under the circumstances of this form of oppression and injustice, underprivileged individuals are subjected to a specific social stigma, whereby the prevalence of a social hierarchy emerges. Consequently, the significance of hard work and meritocracy remains merely a disillusion for those who do not obtain the power and privilege.

Individuals with privilege tend to be in denial when they see subordinate groups as more fortuitous. However, this drives the attention away from examining issues of oppression, but instead bringing privileged individuals into the centre of attention by overlooking the burden faced by marginalized groups. The prevailing social conformity impedes underprivileged students from being acknowledged and supported in Asian schools, especially under the dominant discourse of the Three Teachings. As such, our pictorial representations aim to perpetuate an indepth understanding of equality by supporting the underpinnings of a more empathetic pedagogical framework.

By exchanging our experiences and merging into one place to share commonalities, we seek to identify cases engendered by patterns of oppression with regards to LGBTQ groups, students living with poverty, and individuals with special needs. Building on dialogue and engaging in the process of praxis [8], we reflect upon our stories as the foundation for establishing a keystone for social justice. We embed within our shared stories the analysis of the impact of the principles of the Three Teachings/Religions in Asia: Buddhism, Confucianism, and Taoism.

\section{Methodology}

If you want to know how people feel, what they experience, and what they remember, what their emotions and motives are like, and reasons for acting like they do, why not ask them?

-G.W. Allport

Wang and Burris [16] coined Photo-voice as a qualitative research method that explores the inner world of people who are leading different lives through photographs. This method is known as a creative art form to help researchers listen to the "voice" recorded within the photos that are captured by the participants [17]. Photo-voice is an effective approach that allows researchers to live in the lives of the participants. This research method is an eyeopening experience in doing qualitative research because researchers can contrast with many different viewpoints layered in society.

Inspired by Paulo Freire's liberating education, Photo-voice allows participants to elucidate their thoughts and perceptions of social phenomena through a type of visualism [8]. Utilizing imagery to capture issues among communities and examine 
dilemmas of social conformity, this approach has the potential to encourage its viewers to become visually attuned to the profound meanings behind pictorial representations. This visually-engaging research method provides a window for sharing and simulates personal aesthetics beyond contextual forms of storytelling [18].

The use of Photo-voice can help participants depict their realities and contribute their experiences for social change. Revealing issues from individual stemming from circumstances and unveiling vulnerability and emotions to the public, it provides the opportunity for an open dialogue between participants to voice personal perspectives through narratives of individual encounters. The essence of this community-based participatory research method is to reinforce critical dialogue regarding social issues among groups and communities. In doing so, it endeavours to elicit community awareness and capture the attention of policymakers [17].

\subsection{The Marginalized Voices in Vietnamese Education: Giang-Le's Story}

Mother, no one likes me Why don't they like you?

Mother, because I don't look like any of them What makes you look different? Mother, my body is fleshy and spiny I am rugged and colourless

Do you want beauty for beloved?

Mother, I am afraid of loneliness

Why are you afraid of such?

Mother, I am not strong My little succulent plant

You are strong to turn harshness into beauty

Beauty is in the eye of the beholder

Mother's holding you in the arms of the Earth.

This poem, entitled Spinules, is a dialogue between a mother personifying the Earth and a child personifying a succulent plant. By using a personification technique, I describe my lived experiences of a gay student and teacher in Vietnam. I was bullied by friends and teachers at schools, beaten by my parents at home, and insulted by my colleagues at work, where I served as a teacher. According to Confucian Heritage Culture, Vietnamese Buddhism concepts, and philosophical Taoism, having a non-conforming sexual identity is not accepted and it is perceived as an indication of karma [19]. Institutionalized discrimination also happened to one of my ethnic minority fellows when she was prevented from becoming a teacher in the Vietnamese public schools where Kinh is the population majority and is the main medium of instruction. Another instance of discrimination I witnessed pertained to a female teacher, whose work contract was terminated because she got pregnant and would be on maternity leave in a year. The school administrator's concern was that no one would be able to take over her work at school; hence, the school board decided to rescind her tenurecontract. Due to the prevalence of the three teaching concepts in Vietnam, especially the Vietnamization of Confucianism, the role of women is often associated with devotion to the husband and their livelihood as a housewife. Additionally, the Vietnamese Taoism associates ethnic minorities with shamanistic and ritualistic nature, which makes them underestimated in academia [19]. Therefore, I have constructed my teacher identity as a survivor of the social and cultural norms, which encompass my lived experiences of the oppressed.

\subsection{A Seed of Art within A Teacher and Taiwanese Children with Poverty: Hsiao's Sharing}

Born and raised in Taiwan until the age of thirteen, I moved to Canada for university education. There, I completed my undergraduate degree in fine arts and nourished my passion for art education. I believe in art as an agent for social change and educational transformation.

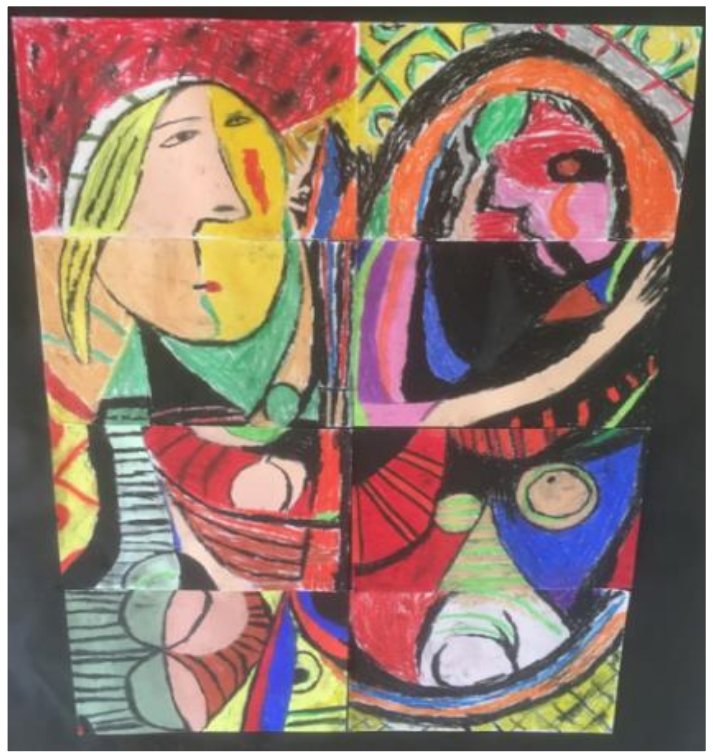

Figure 1. "Girl before a mirror" in the eye of the disadvantaged children

I was an educational assistant in a class of children with special needs who were born in low-income families in Taiwan. Many children did not attain formal education and were forced to quit schooling, as they had to work on the farm with their parents. I learned that school leaders attempted to adapt Buddhist teaching philosophies and inspired teachers to have compassion for the children we were teaching. It was sad for me knowing that these children's parents lost faith in the purpose of 
education; accordingly, they stripped away their offspring's rights to education.

Taiwanese education is deeply influenced by the predominance of Confucianism. Students are expected to never challenge the authority of the teacher, be obedient to instructions, and conform to the dominant beliefs and norms. The impact of Confucianism in Taiwan limited students to become creative and critical thinkers [9]. As such, I strive to engage students with art activities for the purpose of stimulating their learning interests and liberating their creative skills.

I came to a small school located in an underdeveloped area of Taiwan with the hope of bringing the poor children back to classes and motivating them to learn through art-works. Eight children with learning and financial difficulties in a grade 5 class came together to create this collaborative Picasso artwork (see Figure 1). The piece was divided into eight sections as each student created their part before the students combined all the different pieces into one. Each student contributed equally and demonstrated their unique approach of line, colour and texture into the artwork. My experience of teaching art to these students enabled me to understand how art-informed educational techniques can support social justice advocacy for oppressed learners in an Asian context, where Buddhism and Confucianism continue to profoundly impact social values and norms.

\subsection{The invisibility of Students with Special Needs in South Korea: Heo's Lived Experience}

My first perception of vulnerable groups in South Korea was constituted when I was in the third year of middle school. I had a classmate who was three years older than me and who had an intellectual disability. She used to sit alone at the corner side in the back row of the classroom, putting her head on the desk, seldom participating in class. Unfortunately, there was no support worker to help her with her learning difficulties, and myself, as well as, others, including teachers in my class, did not have much interaction with this girl due to a non-verbal prejudice towards her disability and a fear of losing a sense of belonging to their friends' groups.

In South Korea, part of the stigma that is attached to people living with disabilities stems from the Buddhist belief that people are born a certain way as a result of something they did in their previous lives [10]. The concept of karma has laid the foundation of Korean ideology to exclude people with physical, mental, and intellectual difficulties as if they are invisible in their communities.

Unfortunately, the girl living with the mental challenge was completely excluded and isolated in the class, likely causing her to feel extremely frustrated and stress, as she was frequently absent from school. A year later, all of us graduated from middle school, with the exception of that student. A few months later, I was shocked to learn that she gave birth to a child after having been sexually assaulted. This made me feel the agony of guilt for being silent when she needed help from us during the collective discrimination and isolation in the classroom. It left me feeling tormented while I ask myself, "If she had received enough support from teachers and classmates to be able to enjoy being in school, would that bad incident still have happened to her?"

\section{East-to-West Journeys: From Asian to Canadian Education Contexts}

When we three emerging educators and researchers all met in a Canadian institution and shared our lived experiences and our experiences and observations of inequities in Asian education, we realized our educator identities had become transformed through a reflection of the knowledge we acquired in the West. We each might come from different countries in Asia with personal stories to share; however, putting all the stories together, we see a broad colourful picture indicating a significant change in our teacher educator identities. They present us, as emerging educators with courageous hearts, restlessly fighting for justice for the underprivileged, including LGBTQ communities, people with disabilities, and poor children.

\subsection{Giang Le with Tai-Chi Concept}

During my time studying abroad, I have been seeking the possibility of creating a harmonious space where the two contrary educational ideologies, the East and the West, can interweave with each other. At the same time, I am attempting to visualize how this structure of the cosmos is constructed within me and becomes my teacher educator identity.

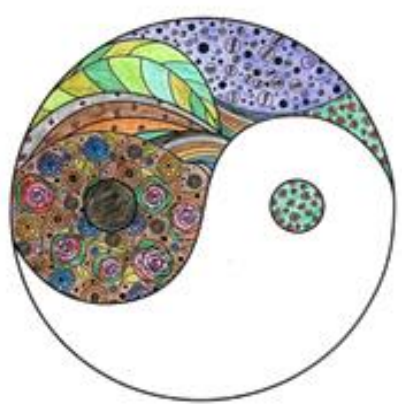

Figure 2. A personalized Tai-Chi image of "Eastmeets-West." 


\author{
Yin Yang \\ Two in One \\ Opponents and Counter-parts \\ Heart of one another \\ Sharing of the soul \\ Embrace each other \\ Justice is the balance \\ We are all the same \\ In balance together \\ In the cycle of Nature
}

I express my educator identity by personalizing a Tai-Chi symbol in Taoism (see Figure 2). It demonstrates a self-in-cohabitation with two different philosophies as two contrary entities: yin and yang. This concept, representing the East and West in harmony to form my identity as a whole, gives rise to each other and interacts with the other [9]. During my studies in a Canadian institution, I would recall the memories of exclusion and sexual discrimination back in the Vietnamese schools of my childhood and adolescence. These lived experiences form my identity of being a social justice advocate for the vulnerable communities in society. Through the Tai-Chi symbol, which captures my personalized embodiment of educational philosophy, I believe that it is essential for today's teachers to embrace diversity, equity, and inclusion in their classrooms. Teachers need to understand these three-folding concepts in contemporary classes, whereby students can benefit from social justice education.

\subsection{Hsiao's Mindset}

Considering myself an artist and an art educator, I recognize art as a tool for transformative learning. Through engaging students aesthetically, educational leaders, including teachers as the classroom leaders, can contribute to both physical and emotional learning of students. I believe teachers have the ability to effectively support student's learning through stimulating their creativity and contribute to the advocacy of social justice.

Although Confucianism still persists as part of the dominant values of Taiwanese education, educators who infuse the principles of social justice into their teaching practices will begin to make a tangible difference in classrooms. Social justice issues and social inequities are important concerns for school leaders to reflect on, while considering the effectiveness of their instructional practices. To properly implement social justice leadership into the school settings, educators must confront and examine social contradictions regarding the impact of politics, social class differences, and social expectations. These signs of social controversy are at the heart of major social and educational impediments for minority students in Taiwanese schools. Therefore, reliance on educators to reinforce equitable teaching is crucial for the marginalized groups.

In my journey from Taiwan to Canada, I learned to embrace multiculturalism by recognizing the radical diversity in the Canadian culture. The Buddhist approach in teaching allows one to engage in transformative learning that involves "a transformation brought about by openness, vulnerability and compassion" [13]. Within this context, my East-to-West experience has allowed me to understand my vulnerability as a person of ethnicminority learning in a Western educational setting. Nevertheless, by acknowledging the roots of my culture, I learned to become open to contributing my experiences to my teaching and learning, while developing empathy for people who share similar difficulties. I have formed my teacher identity as an art educator with a belief in art-based approaches to inspire individuals with and without learning challenges.

\subsection{Heo's Transformed Belief and Identity}

Strongly influenced by the Three Teachings in South Korea, I used to associate disadvantaged people with an abnormality, which made me hesitant to move out of my comfort zone and approach a minority population. However, the agonizing question generated from the incident of the girl living with a mental disability led me to become a social worker in South Korea and pushed me towards social justice in a Canadian educational context.

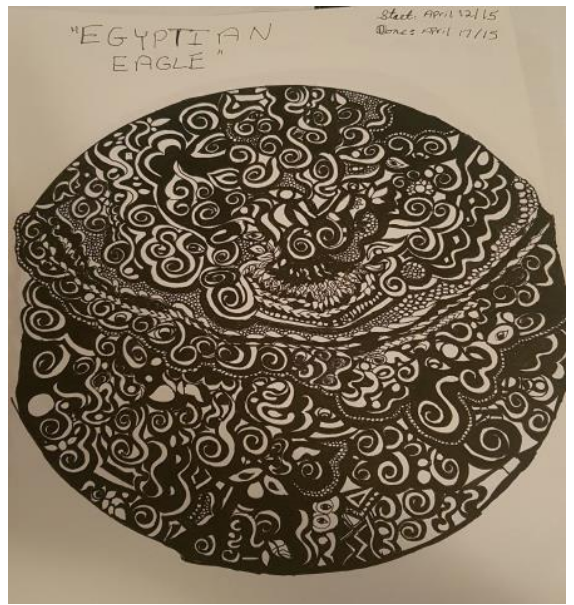

Figure 3. Egyptian Eagle

(used with author's permission)

During Master of Education program in Canada, I met various guest speakers who shared insights and lived experiences, to stimulate my research interests on inclusive education. One of these inspiring guest 
speakers was Jill Kavanaugh who has hemiparesis on the left side of her body. She shared her challenging life story as a person living with a disability in Canada. One of the oppressive experiences in her teenage years was school bullying. Suddenly, Jill's story evoked the memory of the Korean girl who was bullied due to her disability. Through Jill's voice, I could feel the girl's pain and loneliness.

However, unlike the Korean girl who dropped out of school due to negative social and cultural norms around disability, Jill confronted the bullying issue by developing self-advocacy skills and asking for help from a school principal to change the students' mindset of disability as being about diversability, not abnormality. Jill showed me her enchanting drawing "Egyptian Eagle," which took five days to complete (see Figure 3). I was stunned by the sophisticated details in her drawing that represented her diversability. Through Jill's story and drawing, I was able me to change my epistemology of disability constructed by the three teachings in South Korea. That moment provided me with an insight that everyone was born to be different and yet can learn from each other. In order to see the beauty of difference in each individual, we should learn to think critically to evaluate social and cultural norms that are created by the dominant group of society. Therefore, I firmly believe that teachers are the agents of social change who should have a critical lens and keen awareness of social injustice influenced by the misinterpreted three teachings to protect the rights and voices of marginalized students [20].

\subsection{Having a New Lens in the West}

We gather as Asian educators influenced by the preeminence of the Three Teachings in Asian education. The influence of Western philosophy on our current epistemic contexts has a resemblance to our teaching philosophy. Paulo Freire's philosophy of education exemplified pivotal realizations for educators to avoid the banking model of education and strive to engage students in dialogic teaching methods. The essence of this teaching approach is reinforced through emphasizing a problem-posing education that enables individuals to identify classroom oppressions and reflect upon social problems through a process of praxis, consisting of both reflection and action. By critically reflecting on the underlying issues of social inequities in classroom settings, it seeks to liberate students' creative abilities and avert traditional methods of knowledge transmission [8].

After sharing with each other our lived experiences, we recognized the commonalities within our narratives. We analyzed the common threads associated with the photos and divided them into themes. This thematic analysis involved collapsing the information into themes which offered the researchers an in-depth understanding of the experiences and perceptions of the participants [21].

To bracket the data, which are our shared stories of contextualizing our countries of origin and the new place we are now settling in, we put an effort into weaving the various messages into the photos. It is our ultimate purpose to share what we felt through our lived experiences with the readers, and, to artistically connect with them. In this empirical paper, themes representing the findings include the Three Teachings' effects on Asia and self-enlightenment about diversity, inclusion, and equity when in the West.

We would like to emphasize that although we each have different lived experiences; we all have come to the same point of self-construction in our learning journeys in Canada. By using Photo-voice and sharing our stories with prospective readers, we build connections with them and allow the readers to meet with us at the same intersection. The prevalence of social inequities derived from the Three Teachings motivated us in our research, which utilized artinformed techniques to retell our lived experiences through poetry and visual imagery.

\subsection{Art for Healing and Building Relationships}

The intrinsic quality of art can contribute in both verbal and non-verbal ways to provide an understanding of one's values, beliefs, and experience. Creativity involves an aesthetic experience and a pragmatic approach to selfexploration. Art-integrated approaches invite participants to an aesthetic experience through the embodiment of artworks, holding the potential for emotional healing. We present our stories through poetry, drawings, and storytelling to facilitate a form of artistic engagement by establishing a dialogue with our photographs.

Rangel [22] viewed poetry as an artistic approach to holistic pedagogy. It offers a form of genuine discourse with its listeners through expressing meaning by reconciling with individual adversities. When people move outside of their comfort zone to speak of their hardships and sufferings through poetry, they disclose a sense of vulnerability by sharing their sentiments and concerns with the public. Through the process of sharing one's vulnerability, individuals can voice their inner feelings through metaphors, inviting others who share similar experiences to identify with the meanings from the narratives. The authentic dialogue derived from the poems offers an opportunity for individuals to connect meaningfully with their participants, possibly alleviating the pain of their sufferings.

Artistic discourse helps establish a common ground-for participants to develop empathy while 
driving towards an advocacy for social transformation. Artistic practices can be used to create a safe space for individuals to make meaningful connections and express their feelings through aesthetic remarks. By engaging participants emotionally and genuinely, it opens a window for individuals to feel connected with each other and to become mindful of their attitudes towards the experiences of their encounters. This form of social engagement may help facilitate a type of resonance within the group by contributing to social cohesion among individual groups. Additionally, the essence of art practice supports the building of relationships by enabling individuals to identify commonalities and improve their empathy for each other.

\section{Implication}

We believe that the ultimate aim of education is self-actualization and social change. Maslow states that self-actualization refers to the realization of personal full potential [23]. Self-actualization can be attainable through moral education, self-discipline and self-reflection [9]. The three teachings emphasize attainment of self-realization by practicing self-discipline and wise decision making in the given scenario. Similarly, the Greek philosopher Aristotle claims that achieving selfactualization by developing intelligence and characters is a fundamental benefit of education [9].

In this regard, teachers can play a critical role for students' self-actualization and social change involvement as they assist students' character and intelligence development. However, teachers can play an opposite role in the public domain. For instance, one might pass on the dominant social and cultural norms to students, whereas some might challenge students to become critical thinkers who can reassess and reform cultural bias [24]. Consequently, a teacher's willingness to engage in social justice issues can make a huge impact on the direction of the social transformation.

\subsection{Teachers as Agents of Change}

The practice of teaching and learning is a transformative experience for both teachers and students. Bank states that transformation happens when we challenge the way things have been done [25]. Social transformation requires not only individuals' conscious thoughts, feelings and behaviors but also a deep structural shift including our understanding of social location; our relationships with others and the environment; and our sense of possibilities for social justice and selffulfillment [25]. The following three steps can be applied to teachers wishing to practice social justice in a classroom
Firstly, teachers should be mindful of their impact on students' engagement in social change. Mindfulness is a Buddhist term that refers to conscious awareness of one's words, thoughts and behaviors, which can lead one to a deeper awareness of human suffering and oneness of all life [24]. Teachers can exercise mindfulness not only for their personal well-being but also for student engagement and deep respect and compassion for others who suffer from systemic inequality and injustice [24]. To do so, teachers need to take time in class to have a conscientious discussion with students about the meaning of equity and biased social standards that are created by the dominant group in society.

Next, teachers should develop students' critical thinking skills to tear down false notions and beliefs of dominant social norms. Teachers can demonstrate to students how to raise critical questions to challenge unexamined assumptions of personal and social beliefs. This practice can help students to change their perceptions about their social identity and expand ideas to build a new identity without the influence of a false societal ideology.

Thirdly, we as teachers should reposition their roles as an agent of social change to ensure the vision and action of making a better world [20]. Following John Dewey's experiential learning and reflective thinking, teachers can help students learn when and how to speak up to advocate for themselves and others who are oppressed by unexamined social biases [26]. Teachers can invite guest speakers who are currently engaged in social change movement. It will help students to learn about various ways to participate in social change while encouraging their collective efforts to make things happen.

Rios [20] noted that Plato's Republic and; Confucius's Analects alluded to the multifaceted and elusive qualities of education. To understand the versatility in education, individual differences need to be discussed and acknowledged [26]. In addition, flexibility should be the prelude for deeper learning about diversity to overcome one's assumptions and biases toward otherness.

\subsection{Recommendation}

Through this research, we found that our epistemology of injustice through Asian social and education systems was grounded in substantial influence by the Three Teachings: Confucianism, Buddhism, and Taoism. The Confucian roots form the rules of social conduct and a way of life to act according to prescribed norms and to obey teachers and elders ; the cause and effect theory of the Karmic concept in Buddhism is deeply ingrained in Asians' beliefs; the balance of the complex and everchanging dual cosmic energy, yin and yang, in Taoism governs Asians' perception of the inevitable 
existence of - the shadow as a way to part to everything understand the light in the human, social, and the natural world $[2,9]$.

However, the current educational system is influenced by a neoliberal ideology, which promotes the virtues of selfish individualism and competitiveness based on the neoliberal ontology of atomistic self-hood [27]. This ideology has an influence on public education to become a marketoriented and input-output system that renders students passive, fostering uncritical learners [27]. In addition, standardized tests that only measures specific knowledge do not allow teachers to promote students' critical thinking skills in the classroom. More importantly, many teachers struggle with issues of time management and the day-to-day pressure of their professional lives in schools [24]. All these factors can be challenges for teachers to raise awareness of social justice issues in a classroom.

In this paper, we mainly talked about teachers' individual experiences and approaches to raise awareness of social inequity. However, future research on understanding systemic social operation constructed by neoliberal ideology and its relation to our behavior can provide a deeper understanding of the roots of social injustice.

\section{Conclusion}

We conclude our paper by highlighting that there is an interdependence between the lands and the inhabitants in framing the identity of both the landscape and the dwellers. Through our lived experiences from the East to the West, as indicated in the photos, we argue that not only does landscape identity change when affected by changing contexts, but people's social identity also re-shapes itself due to the social location changes. Identity is not a static entity for the landscape or for the inhabitants. The construction of the self can be reformed when a person moves to a new place. Importantly, in our stories of experiencing or witnessing the inequities in different Asian educational contexts, we have identified many similarities regarding the impact of the Three Teaching ideologies: Confucianism, Buddhism, and Taoism. These concepts, rather than religions, create social injustice against marginalized groups, such as LGBTQ communities, women in the workplace, ethnic minorities, and students with diversities. Finally, the most significant finding in our study is how the educators with the lived or witnessed experiences of inequities in their original educational contexts can internalize the critical social justice principles: diversity, equity, and inclusion, in a new place as a result of their transcultural journeys.

\section{Acknowledgements}

We acknowledge the contribution of Jill Kavanaugh for her artwork for our research data. We recognize eight grade-five students from Chao-Tung Elementary school in Taiwan who gave us authority to include their drawings in the study. We are grateful to Krystyna Henke and Drs. Georgann Cope Watson, Patricia Neufeld, and Michele Sorensen at Thompson Rivers University for their insightful comments on this paper. This project was co-funded by Blanche E Snell Estate Fund: Project Ref. No. BESE 1819-3 and Thompson Rivers University Students' Union.

\section{References}

[1] Dewey, John, Experience and Education, Macmillan Co., New York, 1938

[2] Fowler, Jeaneane D, Chinese Religions: Beliefs, Sussex Academic Press, Brighton, 2008

[3] Haartsen, T., Groote, P., \& Huigen, P. P. (Eds.), Claiming Rural Identities: Dynamics, Contexts, Policies, Van Gorcum, 2000.

[4] Daynes, R. "Social Location and Practising as an Ally in Community Development", Research and Perspectives on Development Practice, Kimmage Development Studies Centre, Dublin, 2007, pp. 1-16.

[5]Stobbelaar, D. J., \& Pedroli, B. "Perspectives on Landscape Identity: A Conceptual Challenge", Landscape Research, 36(3), Taylor \& Francis 1td, 2011, pp. 321-339.

[6] Paasi, A. "Bounded Spaces in The Mobile World: Deconstructing Regional Identity", Tijdschrift Voor Economische en Scoiale Geografie, 93(2), Wiley Blackwell, 2002, pp. 137-148.

[7] Worchel, Stephen, and William G. Austin, (Eds.), The Social Psychology of Intergroup Relations, Cole Publishing Company, Michigan, 1979.

[8] Freire P, Ramos MB, Shor I, Macedo DP, Pedagogy of the Oppressed: 50th Anniversary Edition. Bloomsbury Academic, New York, 2018

[9] Ho, D.Y., "Selfhood and Identity in Confucianism, Taoism, Buddhism, and Hinduism: contrasts with the West", Journal for the Theory of Social Behaviour, 25(2), Wiley Blackwell, 1995, pp.115-139.

[10] Lam, Chow S., et al. "Chinese Lay Theory and Mental Illness Stigma: Implications for Research and Practices." Journal of Rehabilitation, 76(1), National Rehabilitation Association, 2010, pp. 35-40.

[11] Csikszentmihalyi, M., Flow. The Psychology of Optimal Experience, Harper \& Row, New York, 1990.

[12] Schumm, Darla, and Michael Stoltzfus, Beyond models: 'Some Tentative Daoist Contributions to Disability Studies' In Disability and Religious Diversity, Palgrave Macmillan, New York, 2011, pp. 103-122. 
[13] Gates, G.S. "Awakening to School Community: Buddhist Philosophy for Educational Reform," The Journal of Educational Thought, 39(2), JSTOR, 2005, pp. 149-173.

[14] Irwin, Rita L., et al. "A/r/Tography as Living Inquiry Through Art and Text" Qualitative Inquiry, 11(6), Sage Publications, 2005, p. 897.

[15] D. Thiessen \& A. Cook-Sather, International handbook of student experiences in elementary and secondary school, Springer, Dordrecht, 2007, pp. 347-374.

[16] Wang, C. C., \& Burris, M. "Photovoice: Concept, Methodology, and Use for Participatory Needs Assessment", Health Education and Behavior, 24(3), Sage Publications, Thousand Oaks, CA, 1997, pp. 369-387.

[17] Leavy, P. Arts-based Research Design. In P. Leavy (Ed.), Research Design: Quantitative, Qualitative, Mixed Methods, Arts-based, and Community-based Participatory Research Approaches, Guilford Press, New York, 2017.

[18] Nykiforuk, C.I., Vallianatos, H. and Nieuwendyk, L.M."'Photovoice As a Method for Revealing Community Perceptions of the Built and Social Environment", International Journal of Qualitative Methods, 10(2), Sage Publications, London, 2011 pp.103-124.

[19] Vuong, Q. H., Bui, Q. K., La, V. P., Vuong, T. T., Nguyen, V. H. T., Ho, M. T., \& Ho, M. T. "Cultural Additivity: Behavioural Insights from The Interaction of Confucianism, Buddhism, and Taoism in Folktales". Palgrave Communications, 4(1), Springer Nature, New York, 2018, pp. 143.

[20] Ríos, Raquel, Teacher Agency for Equity: A Framework for Conscientious Engagement, Routledge, New York, 2018.

[21] Creswell, J. W., Educational Research: Planning, Conducting, and Evaluating Quantitative and Qualitative Research, Pearson, New Jersey, 2015.

[22]Nicole, R., "An Examination of Poetry for the People: A Decolonizing Holistic Approach to Arts Education", Educational Studies :Journal of the American Educational Studies Association, Taylor \& Francis ltd, Berkeley, 52(6), 2016, pp. 536-551.

[23] Maslow, A. H., "The Instinctoid Nature of Basic Needs", Journal of Personality, 22(3), Wiley Blackwell, 1954, p. 326.

[24] Cannon, J., 'Education as the Practice of Freedom: A Social Justice Proposal for Mindfulness Educators'. In Handbook of Mindfulness, Springer Nature, Switzerland, 2016, pp. 397-409.

[25] Banks, J.A., "The Historical Reconstruction of Knowledge about Race: Implications for Transformative Teaching" Educational Researcher, 24(2), Sage Publications, 1995, pp.15-25.
[26] Berila, B., Integrating Mindfulness into AntiOppression Pedagogy: Social Justice in Higher Education, Routledge, New York, 2016.

[27] Kretz, L., 2014. "Ecological Identity in Education: Subverting the Neoliberal Self" Leadership and Research in Education, 1, Ohio Council of Professors of Educational Administration, 2014 pp.4-21. 